\title{
Spacer inhalation technique and deposition of extrafine aerosol in asthmatic children
}

\author{
C.M. Roller*, G. Zhang*, R.G. Troedson*, C.L. Leach", P.N. Le Souëf* \\ and S.G. Devadason*
}

ABSTRACT: The aim of the present study was to measure airway, oropharyngeal and gastrointestinal deposition of ${ }^{99 \mathrm{~m}} \mathrm{Tc}$-labelled hydrofluoroalkane-beclomethasone dipropionate after inhalation via a pressurised metered-dose inhaler and spacer (Aerochamber Plus ${ }^{\mathrm{TM}}$ ) in asthmatic children.

A group of 24 children (aged 5-17 yrs) with mild asthma inhaled the labelled drug. A total of 12 children took five tidal breaths after each actuation (tidal group). The other 12 children used a slow maximal inhalation followed by a 5-10-s breath-hold (breath-hold group). Simultaneous anterior and posterior planar $\gamma$-scintigraphic scans (120-s acquisition) were recorded.

For the tidal group, mean \pm SD lung deposition (\% ex-actuator, attenuation corrected) was $35.4 \pm 18.3,47.5 \pm 13.0$ and $54.9 \pm 11.2$ in patients aged 5-7 $(n=4), 8-10(n=4)$ and 11-17 yrs $(n=4)$, respectively. Oropharyngeal and gastrointestinal deposition was $24.0 \pm 10.5,10.3 \pm 4.4$ and 10.1 \pm 6.2. With the breath-hold technique, lung deposition was $58.1 \pm 6.7,56.6 \pm 5.2$ and $58.4 \pm$ 9.2. Oropharyngeal and gastrointestinal deposition was $12.9 \pm 3.2,20.1 \pm 9.5$ and 20.8 \pm 8.8 .

Inhalation of the extrafine formulation with the breath-hold technique showed significantly improved lung deposition compared with tidal breathing across all ages. Oropharyngeal and gastrointestinal deposition was markedly decreased, regardless of which inhalation technique was applied, compared with a previous paediatric study using the same formulation delivered via a breath-actuated metered-dose inhaler.

KEYWORDS: Children, deposition study, inhalation technique, spacers

A sthma is recognised as a chronic inflammatory disease affecting the large and small airways of both adults and children [1-3]. Inhaled corticosteroids (ICS) are recommended as prophylactic treatment of asthma in children with persistent asthma symptoms [4,5]. Topical airway targeting largely determines the efficacy of ICS [6, 7]. Factors affecting efficacy include age, the particle size of the aerosol, the delivery device, the inhalation profile and the geometry of the airways $[8,9]$.

Chlorofluorocarbon (CFC) propellants are being phased-out and replaced with hydrofluoroalkanes (HFA) in pressurised metered-dose inhalers (pMDI). Beclomethasone dipropionate (BDP) reformulated with HFA-134a (HFA-BDP or $\mathrm{QVAR}^{\mathrm{TM}}$; 3M Health Care Ltd, Loughborough, UK) produces an extrafine aerosol that has a mass median aerodynamic diameter of $\sim 1.1 \mu \mathrm{m}$ [10] as the propellant evaporates. The formulation has a lower spray force, a warmer temperature and is in solution, rather than suspension [11]. These changes in the properties of the aerosol are associated with improved lung deposition and improved penetration of the aerosol into the peripheral airways. This may be associated with improved asthma control and health-related quality of life [12, 13]. Clinical studies have shown efficacy of HFA-BDP at half the dose of CFC-BDP [14-16].

High lung deposition of HFA-BDP delivered after inhalation via a breath-actuated MDI (Autohaler ${ }^{\mathrm{TM}}$; 3M Health Care Ltd) has been shown in a previous paediatric deposition study [17]. However, gastrointestinal deposition was $\leqslant 60 \%$ in children aged $5-14$ yrs after inhalation via Autohaler ${ }^{\mathrm{TM}}$. Drug swallowed into the gastrointestinal tract has little therapeutic value and may contribute to side-effects [11, 18]. Spacer devices attached to pMDIs are recommended for children using inhaled corticosteroids, to reduce the impaction of the larger drug particles in the oropharynx and minimise drug reaching the gastrointestinal tract $[19,20]$. The aim of the present study was to use $\gamma$-scintigraphy to assess the deposition of HFA-BDP delivered via a pMDI with an attached spacer (Aerochamber Plus ${ }^{\mathrm{TM}}$; Trudell Medical International, London, Canada)
AFFILIATIONS

*UWA School of Paediatrics and Child Health, and

\#Dept of Nuclear Medicine, Princess Margaret Hospital for Children, Perth, Western Australia, and "Lovelace Respiratory Research Institute, Albuquerque, NM, USA.

CORRESPONDENCE

C.M. Roller

UWA School of Paediatrics and

Child Health

Princess Margaret Hospital

for Children

GP0 D184 Perth

Western Australia 6840

Fax: 61893882097

E-mail: croller@meddent.uwa.edu.au

Received:

April 132006

Accepted after revision:

September 092006

SUPPORT STATEMENT

This work was supported by the Child Health Research Foundation of Western Australia, Perth; and the National Health and Medical Research Council of Australia, Canberra, Australia. This study was partially funded by 3M Pharmaceuticals (St Paul, MN, USA).

STATEMENT OF INTEREST None declared. 
in children aged 5-17 yrs. It was hypothesised that oropharyngeal and gastrointestinal deposition of HFA-BDP could be markedly reduced, compared with the delivery of HFA-BDP via Autohaler ${ }^{\mathrm{TM}}$, while maintaining high lung deposition of the extrafine particles.

Younger children are able to use tidal breathing with spacer devices, thereby minimising problems coordinating their inhalation with actuation. The Global Initiative for Asthma guidelines [21] suggest that, for children who can use the Aerochamber Plus ${ }^{\mathrm{TM}}$, the optimal inhalation technique is a slow, deep breath in, followed by a breath-hold of $\sim 10 \mathrm{~s}$. It is recommended that children who are unable to perform this inhalation technique use tidal breathing. Therefore, the present authors also assessed the differences in total body deposition of HFA-BDP delivered via a pMDI and spacer with tidal breathing compared with the slow single maximal inhalation technique followed by a 10-s breath-hold, where possible. All children included in the present study were able to maintain the breath-hold for $a \geqslant 5 \mathrm{~s}$. Both the tidal breathing technique and the breath-hold technique are commonly recommended by clinicians when training children to use pMDI and spacer.

\section{METHOD}

\section{Subjects}

A total of 25 children (all male) aged 5-17 yrs with mild, stable asthma were recruited from outpatient clinics at the Princess Margaret Hospital for Children (Perth, Western Australia). On the study day, each child had weight, height and lung function measured (table 1). Only those patients with a forced expiratory volume in one second (FEV1) $>80 \%$ of predicted values $(\%$ pred) were enrolled in the study [22]. All children were withheld any bronchodilator medication for $4 \mathrm{~h}$ prior to the study. In total, 23 children inhaled two doses of Ventolin 8 (GlaxoSmithKlein Pty Ltd, Melbourne, Australia; $100 \mu \mathrm{g} \cdot \mathrm{dose}^{-1}$ ) $30 \mathrm{~min}$ prior to scintigraphy. One child did not receive Ventolin ${ }^{\circledR}$ prior to scintigraphy, but his FEV1 was $98 \%$ pred. One child was excluded from the study because he could not attain an FEV1 $>80 \%$.

Exclusion criteria were: past or present diagnoses of cardiovascular, renal or liver disease; known hypersensitivity to BDP;

\begin{tabular}{|c|c|c|c|c|c|}
\hline \multirow{2}{*}{$\begin{array}{l}\text { TABLE } 1 \\
\text { Age group } \\
\text { yrs }\end{array}$} & \multicolumn{5}{|c|}{$\begin{array}{l}\text { Height, weight, forced expiratory volume in one } \\
\text { second (FEV1) and forced vital capacity (FVC) in } \\
\text { the tidal and breath-hold groups }\end{array}$} \\
\hline & $\begin{array}{c}\text { Subjects } \\
n\end{array}$ & $\begin{array}{l}\text { Height } \\
\text { cm }\end{array}$ & $\begin{array}{c}\text { Weight } \\
\text { kg }\end{array}$ & $\begin{array}{c}\text { FEV }_{1} \\
\text { L }\end{array}$ & $\begin{array}{c}\text { FVC } \\
\text { L }\end{array}$ \\
\hline \multicolumn{6}{|l|}{ Tidal } \\
\hline $5-7$ & 4 & $124.1 \pm 4.8$ & $25.1 \pm 4.1$ & $1.5 \pm 0.2$ & $1.7 \pm 0.2$ \\
\hline $8-10$ & 4 & $136.7 \pm 8.0$ & $29.3 \pm 4.4$ & $1.9 \pm 0.3$ & $2.3 \pm 0.3$ \\
\hline $11-17$ & 4 & $159.4 \pm 17.2$ & $53.9 \pm 19.5$ & $3.3 \pm 1.0$ & $3.9 \pm 1.0$ \\
\hline \multicolumn{6}{|l|}{ Breath-hold } \\
\hline $5-7$ & 4 & $119.1 \pm 5.0$ & $23.6 \pm 0.6$ & $1.8 \pm 0.3$ & $1.8 \pm 0.1$ \\
\hline $8-10$ & 4 & $130.7 \pm 14.0$ & $30.4 \pm 8.6$ & $1.7 \pm 0.5$ & $2.0 \pm 0.6$ \\
\hline $11-17$ & 4 & $155.3 \pm 8.5$ & $42.9 \pm 5.3$ & $2.4 \pm 0.3$ & $3.0 \pm 0.3$ \\
\hline
\end{tabular}

Data are presented as mean $\pm \mathrm{SD}$ previous inclusion in a radiolabel deposition study for research purposes; exacerbation of asthma symptoms within the previous 4 weeks; or inability to perform the required breathing technique.

\section{Inhalation technique}

Each child was trained to perform either tidal breathing $(n=12)$ or a single maximal inhalation followed by a 5-10-s breathhold $(n=12)$. A low-resistance filter (Curity®Anesthesia Filter; Tyco Healthcare, Mansfield, MA, USA) was attached to the mouthpiece of an Aerochamber Plus ${ }^{\mathrm{TM}}$ spacer so that the child could rehearse the tidal breathing technique with five tidal breaths from the spacer after firing $100 \mu \mathrm{g}$ of BDP. Alternatively, the child rehearsed with a single maximal inhalation, followed by a 5-10-s breath-hold. This was repeated 3-5 times, so that the child understood the correct technique before inhaling the radiolabelled BDP. These groups are referred to as tidal and breath-hold, respectively. The children were divided into three subgroups according to age: $5-7$ yrs $(n=4), 8-10$ yrs $(n=4)$ and $11-17$ yrs $(n=4)$, in order to compare results with the previous paediatric deposition study which used the Autohaler ${ }^{\mathrm{TM}}$ device to deliver the same formulation. Before the deposition study, the spacers were soaked in a dilute solution of detergent (Pyroneg; DiverseyLever Australia Pty Ltd, Sydney, New South Wales, Australia) for $\geqslant 10 \mathrm{~min}$ and then drip-dried.

\section{$\gamma$-Scintigraphy}

A double-headed $\gamma$-camera (GCA 7200DI; Toshiba Australia, Perth, Australia) was used for scintigraphic imaging. Each subject had an initial 2-min anterior transmission scan in the supine position using a uniform flood source containing $37 \mathrm{MBq}$ technetium $\left({ }^{99 \mathrm{~m}} \mathrm{Tc}\right)$. Attenuation factors were derived for each child due to absorption by body tissues as described by MACEY and MARSHALL [23]. After the transmission scan, each child inhaled 2-4 doses of ${ }^{99 \mathrm{~m}} \mathrm{Tc}$-HFA-BDP $(200-400 \mu \mathrm{g})$ so that the dose was within 2-4 MBq, depending on age.

Immediately after inhaling the ${ }^{99 \mathrm{~m}}$ Tc-HFA-BDP, each child was instructed to exhale gently into a low-resistance filter (Curity®Anesthesia Filter) so that the exhaled fraction of radioactive drug could be assessed. The child was then repositioned under the $\gamma$-camera and simultaneous anterior and posterior planar scintigraphic images (120-s acquisition time) of the chest and abdomen and lateral images of the upper airways were obtained. This was followed by a 2-min image of the actuator, spacer and filter. Regions of interest were defined for each of the images and total counts were determined for the right and left lungs, stomach, oesophagus, mouth, oropharynx, actuator, spacer and filter. Each total count was corrected for background counts and decay-corrected to the time of the patient scan. The attenuation factors for each child were derived, as well as the geometric means of corresponding anterior and posterior counts. The dose deposited in the lungs was expressed as a percentage of the total dose delivered from the actuator (i.e. \% ex-actuator). The pulmonary regional distribution was determined by calculating the ratio of peripherally (P) and centrally (C) deposited activity. The central region was measured as half the width of the lung and one-third of the height. The remaining region was measured as the peripheral region. 


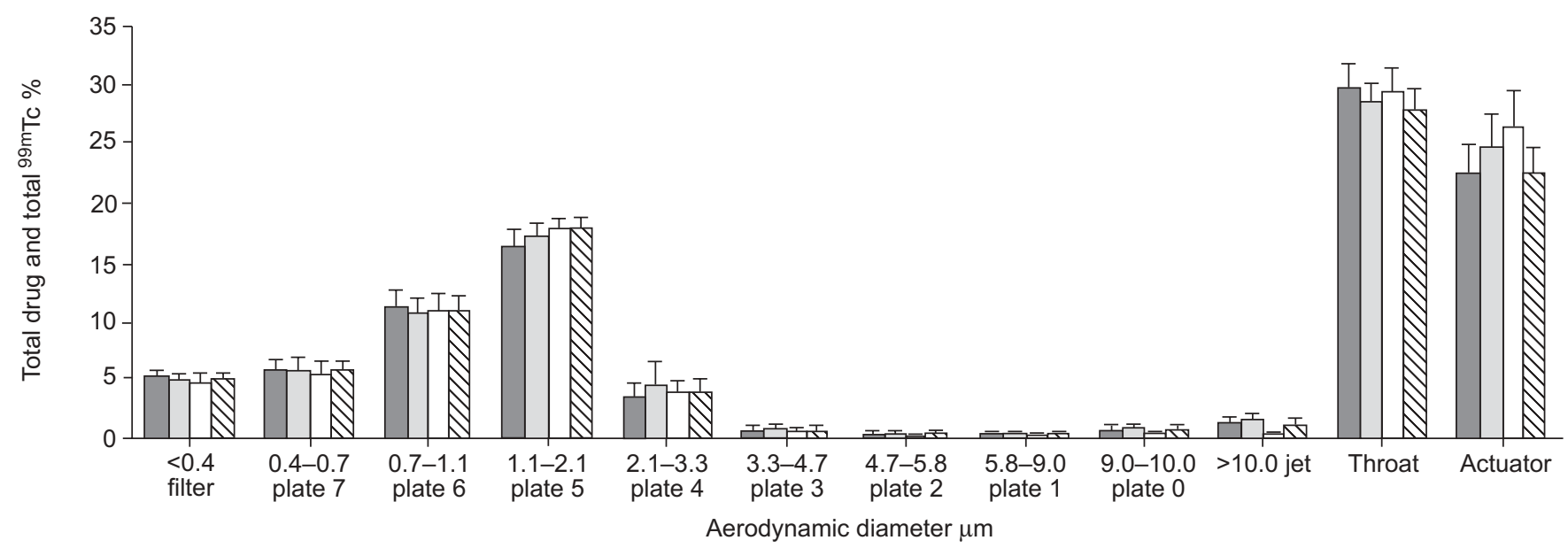

FIGURE 1. Size distributions of $\operatorname{QVAR}^{\mathrm{TM}}$ (3M Health Care Ltd, Loughborough, UK) particles before radiolabel (before label; $\square$ ), after radiolabel (after label; $\square$ ) and ${ }^{99 \mathrm{~m}} \mathrm{Tc}(\square)$ in the corresponding size fractions and QVAR ${ }^{\mathrm{TM}}$ particles after radioactive decay (decay label; $\mathbb{\mathbb { }}$ ). Data are presented as mean \pm SD percentages of total dose. $n=15$.

\section{Ethical considerations}

Approval for the study was granted by the Princess Margaret Hospital Ethics Committee. Informed consent was obtained from parents and children. The maximum level of radiation dispensed to each patient (2-4 MBq, depending on age) was approved by the Radiation Safety Officer at Royal Perth Hospital (Perth, Western Australia) and was equivalent to an effective dose of $0.1 \mathrm{mSv}$. The Australian Radiation Protection and Nuclear Safety Agency recommends a limit of $0.5 \mathrm{mSv}$ for the annual effective dose in children $\leqslant 18$ yrs participating in biomedical research [24].

\section{Radiolabelling of HFA-BDP}

Radiolabelling of HFA-BDP was performed using a method previously described by LEACH et al. [14]. Sodium pertechnetate $\left(\mathrm{Na}^{99 \mathrm{~m}} \mathrm{TcO}_{4}\right)$ was extracted into chloroform as tetraphenylarsonium pertechnetate $\left(\mathrm{AsPh}_{4} \mathrm{TcO}_{4}\right)$, followed by evaporation of the chloroform under a gentle stream of nitrogen. A commercial canister of HFA-BDP $\left(\mathrm{QVAR}^{\mathrm{TM}}\right)$ was weighed, supercooled in liquid nitrogen, decrimped and the contents rapidly poured into the ${ }^{99 \mathrm{~m}}$ Tc-lined canister. The canister was recrimped and reweighed to determine whether significant propellant loss had occurred.

Using an eight-stage nonviable Anderson Cascade Impactor (Copley Scientific, Nottingham, UK), the particle size distribution before and after radiolabelling confirmed that the contents of the commercial canister were not changed by the radiolabelling procedure. The pMDI was primed and then inserted into the "throat" of the cascade impactor. A total of 20 doses of HFA-BDP $\left(100 \mu \mathrm{g} \cdot\right.$ actuation $\left.^{-1}\right)$ were drawn into the cascade impactor at a continuous flow of $28.3 \mathrm{~L} \cdot \mathrm{min}^{-1}$ in order to optimise analytical sensitivity and to minimise bounce effects [25].

The particles were either deposited on the standard United States Pharmacopeia throat, on the jet stage, or on one of the eight impaction plates and absolute filter, depending on aerodynamic size. They were then washed off with $25 \mathrm{~mL}$ ethanol. The absorbance of BDP (wavelength $238 \mathrm{~nm}$ ) was measured in each wash by ultraviolet spectrophotometry (Shimadzu UV-1601; Shimadzu, Kyoto, Japan). The standard curve for BDP was linear $\left(\mathrm{r}^{2}=1.00\right)$ for concentrations $\leqslant 20 \mu \mathrm{g} \cdot \mathrm{mL}^{-1}$.

A comparison of the mass of BDP with ${ }^{99 \mathrm{~m}} \mathrm{Tc}$ activity levels for each fraction, measured by ionisation chamber (Atomlab 200 dose calibrator; Gammasonics, Sydney, Australia), confirmed that ${ }^{99 \mathrm{~m}} \mathrm{Tc}$ acts as a suitable marker for BDP (fig. 1). It has been shown that BDP levels, determined by high-performance liquid chromatography, match the radioactive counts of ${ }^{99} \mathrm{~m} \mathrm{Tc}$, measured by ionisation chamber, when only three doses of ${ }^{99 \mathrm{~m}} \mathrm{Tc}-\mathrm{HFA}-\mathrm{BDP}\left(100 \mu \mathrm{g} \cdot\right.$ actuation $\left.^{-1}\right)$ were sampled and the same radiolabelling procedure was used [14]. The fine particle fraction (FPF) of both radiolabel and drug was calculated as the proportion of the ex-valve dose in particles $<4.7 \mu \mathrm{m}$ in diameter (sum of Anderson plate 3-filter).

The particle size distribution of BDP from each $\mathrm{QVAR}^{\mathrm{TM}}$ canister used for patient inhalation studies $(n=15)$ was measured both pre- and post-labelling. On each study day a comparison was made between the particle size distribution and output of drug (BDP) before and after radiolabelling, with the corresponding ${ }^{99 \mathrm{~m}} \mathrm{Tc}$ distribution, to ensure that the contents of the commercial canister were not altered by the radiolabelling procedure. The total ${ }^{99 \mathrm{~m}} \mathrm{Tc}$ output was measured to ensure that the ex-actuator dose of activity delivered to each subject was $\leqslant 2-4 \mathrm{MBq}$. After the decay of ${ }^{99 \mathrm{~m}} \mathrm{Tc}$, another particle size distribution of BDP from the labelled canister was performed to verify the integrity of the transfer of contents from the commercial canister (fig. 1).

\section{Statistical analysis}

With the sample size selected (12 children in each of the experiment groups: tidal breathing and breath-hold), the study had $>80 \%$ power to detect a $40 \%$ difference in lung dose, according to a pre-study calculation. Lung doses, oropharyngeal and gastrointestinal doses and spacer and filter deposition of ${ }^{99 \mathrm{~m}} \mathrm{Tc}-\mathrm{HFA}-\mathrm{BDP}$ were presented as mean $\pm \mathrm{SD}$. The difference in the regional distribution of ${ }^{99 m}$ Tc-HFA-BDP 


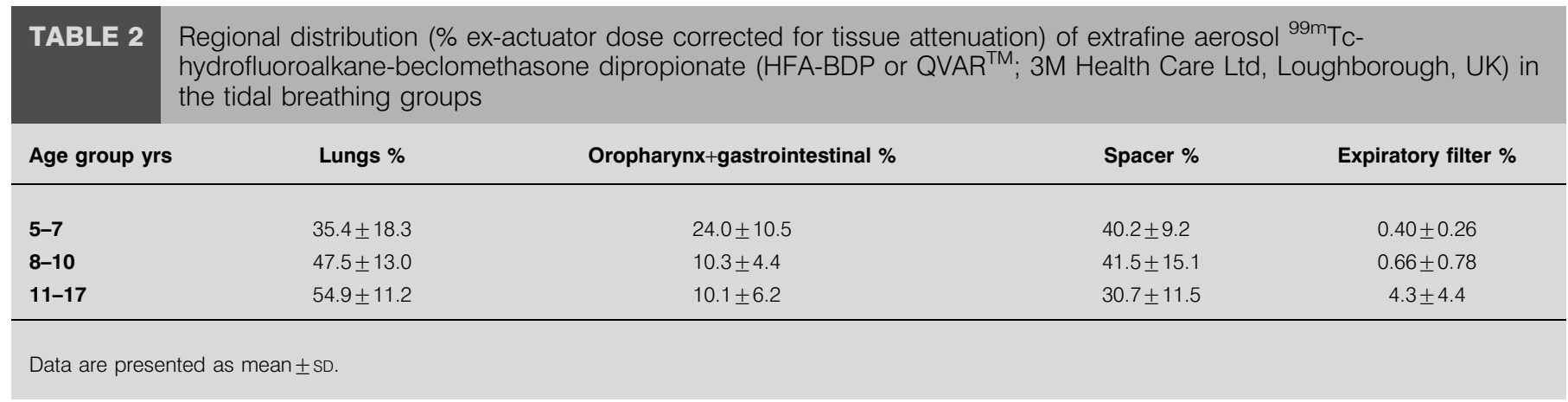

was compared between the tidal and breath-hold groups using unpaired t-tests and between the three age groups using ANOVA, respectively. Correlations were estimated between regional distribution and lung function parameters using the bivariate correlations procedure. ANOVA and ANCOVA were further used to compare the means of lung and oropharyngeal and gastrointestinal deposition between breath-hold and tidal groups. In order to minimise the influence of lung function parameters, adjusted means and 95\% confidence intervals of lung deposition were presented. The adjusted means were estimated using general linear models, assuming that children in breath-hold and tidal groups had the same value of forced vital capacity (FVC). The adjustment aimed to minimise the influence of the difference in FVC on the lung deposition between the two groups. The interaction on oropharyngeal and gastrointestinal deposition was also explored between age and groups (breath-hold and tidal) using general linear models.

\section{RESULTS}

During the in vitro validation procedure, the mean $\pm \mathrm{SD}$ total amount of BDP (ex-valve dose) recovered from the actuator and cascade impactor for these inhalers $(n=15)$ was $96.6 \pm 4.2 \mu \mathrm{g}$ before radiolabelling, $102.5 \pm 3.0 \mu \mathrm{g}$ immediately after radiolabelling and $95.1 \pm 3.8 \mu \mathrm{g}$ after radioactive decay. FPF $($ mean $\pm \mathrm{SD})$ was $56.9 \pm 2.5,58.1 \pm 2.5,58.8 \pm 2.7$ and $59.4 \pm 2.1 \%$ for before label, after label, radiolabel $\left({ }^{99 \mathrm{~m}} \mathrm{Tc}\right)$ and decay label, respectively (fig. 1).

Attenuation factors (AF) were generated using the square root of the counts per pixel in the transmission image of the ${ }^{99 \mathrm{~m}} \mathrm{Tc}$ flood source divided by the counts per pixel in regions of interest (ROI) attenuated by each child [23]. AFs for lung, mouth, throat, oesophagus and stomach ROI ranged 1.7-2.7. The regional distribution of ${ }^{99 \mathrm{~m}} \mathrm{Tc}$-HFA-BDP in lungs, oropharynx and gastrointestinal tract, spacer and expiratory filter in the tidal group is shown in table 2. The total body distribution is demonstrated in the anterior $\gamma$-scintigraphic images in figure 2. The average proportion of lung deposition for the tidal group was $45.9 \%$ (range $14.4-67.9 \%$ ). The coefficient of variation $(\mathrm{CV})$ was $34.0 \%$. The P:C ratio for the tidal group was $2.3 \pm 0.5$. The proportion of deposition in the lungs increased with age and lung function, although it was not statistically significant. Lung deposition tended to increase with age and lung function and was positively correlated with FVC $\left(r^{2}=0.306, p=0.062\right)$, FEV1 $\left(r^{2}=0.244, p=0.102\right)$, height $\left(r^{2}=0.304, p=0.063\right)$ and weight $\left(r^{2}=0.272, p=0.082\right)$. Since only four children were studied in each of the age groups the statistical power was 0.29 to detect the differences in lung depositions (table 2) between the age groups.

In the breath-hold group (table 3), the average lung deposition of ${ }^{99 m}$ Tc-HFA-BDP was $>50 \%(45.9-68.1 \%)$. The CV was $11.4 \%$. No significant difference in lung deposition was found between the three age groups. No correlation was found between lung dose, weight, height and lung function parameters FVC and FEV1. The P:C ratio for the breath-hold group was $2.3 \pm 0.4$.
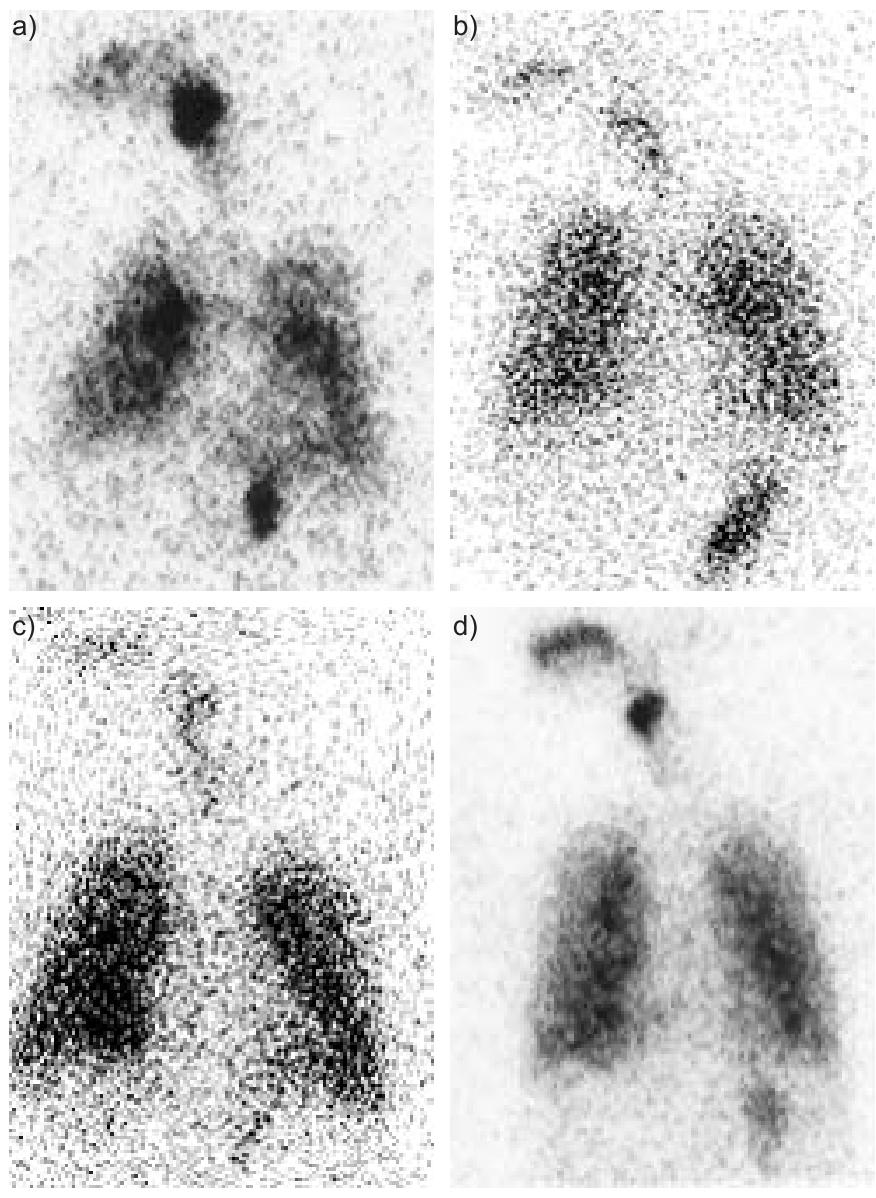

d)

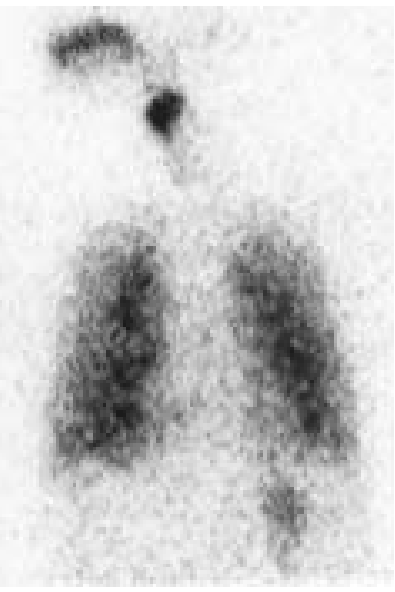

FIGURE 2. Anterior $\gamma$-scintigraphic scans showing regional distribution of radiolabelled QVAR $^{\mathrm{TM}}$ (3M Health Care Ltd, Loughborough, UK) in asthmatic children a) age 5-7 yrs tidal and b) 5-7 yrs breath-hold; c) age 11-17 yrs tidal and d) 11-17 yrs breath-hold. 
TABLE 3 Regional distribution (\% ex-actuator dose corrected for tissue attenuation) of extrafine aerosol (QVAR ${ }^{\mathrm{TM}}$; 3M Health Care Ltd, Loughborough, UK) in groups using the single maximal inhalation with breath-hold

\begin{tabular}{llccc} 
Age group yrs & Lungs $\%$ & Oropharynx+gastrointestinal \% & Spacer \% & Expiratory filter \% \\
\hline $\mathbf{5 - 7}$ & $58.1 \pm 6.7$ & $12.9 \pm 3.2$ & $24.1 \pm 7.0$ & \\
$\mathbf{8 - 1 0}$ & $56.6 \pm 5.2$ & $20.1 \pm 9.5$ & $18.2 \pm 1.6$ & $5.9 \pm 4.7$ \\
$\mathbf{1 1 - 1 7}$ & $58.4 \pm 9.2$ & $20.8 \pm 8.8$ & $20.3 \pm 4.5$ & $0.1 \pm 4.6$ \\
\hline
\end{tabular}

Data are presented as mean \pm SD

Differences in lung deposition between tidal and breath-hold were compared by adjusting for FVC, so that the difference between the two groups was independent of lung function and directly related to inhalation technique. Figure 3 compares the difference in lung deposition between tidal and breath-hold. The total difference in the adjusted means of lung deposition across the three age groups was statistically significant $(n=12$, $\mathrm{p}=0.006$ ). In children aged 5-7 yrs, the adjusted mean of lung deposition in the breath-hold group was 1.6 times higher than that in the tidal group, although the difference was not statistically significant due to the small sample size. In the youngest age group, the P:C ratio was $2.5 \pm 0.2$ for breath-hold compared with $2.0 \pm 0.5$ for tidal breathing.

Figure 4 shows the comparison of the combined oropharyngeal and gastrointestinal deposition of ${ }^{99 \mathrm{~m}} \mathrm{Tc}-\mathrm{HFA}-\mathrm{BDP}$ delivered via a pMDI spacer. This was reduced two- to four-fold compared to the previously published dose of $40-60 \%$ obtained after inhalation of the same formulation via Autohaler $^{\mathrm{TM}}$ [17]. For the tidal group, children aged 5-7 yrs had a higher oropharyngeal and gastrointestinal deposition than those in the breath-hold group. Conversely, children aged 8-17 yrs had higher oropharyngeal and gastrointestinal deposition with breath-hold relative to tidal (fig. 4). The crossover interaction between age and tidal and breathhold groups for oropharyngeal and gastrointestinal deposition was statistically significant $(p=0.016)$. It was noted that

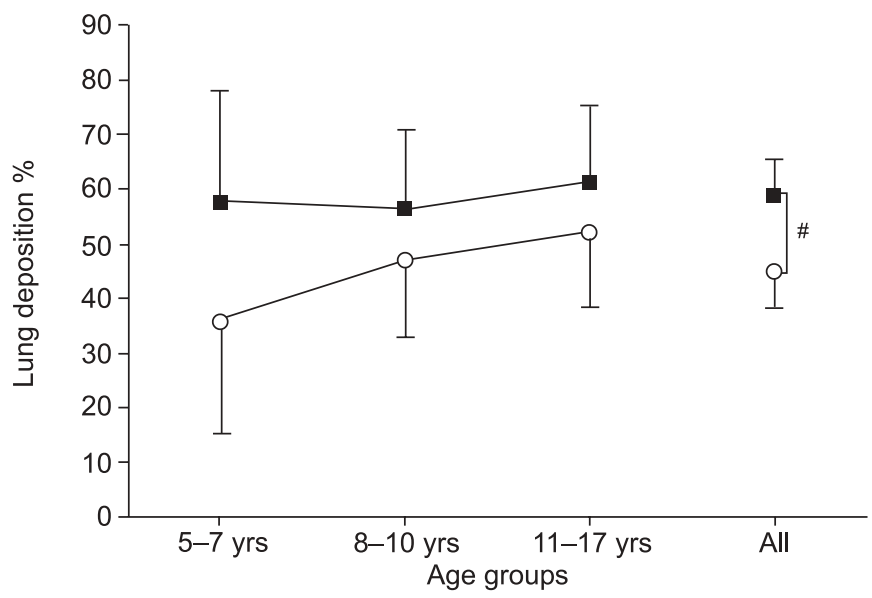

FIGURE 3. Adjusted means of lung deposition (\% ex-actuator, adjusted for forced vital capacity) in the two study groups: breath-hold $(\boldsymbol{\square})$ and tidal $(\bigcirc)$. ANOVA and ANCOVA were used to compare the means of lung deposition between breath-hold and tidal. ${ }^{*}: p=0.006$. considerably more drug was retained in the spacer with tidal than with breath-hold technique across all ages $(n=12$, $\mathrm{p}<0.001$ ).

The exhaled filter dose was difficult to obtain as some children coughed before breathing onto the filter [26]. The present authors measured a mean exhaled filter dose $<5 \%$ across all ages, which is comparable to the mean exhaled filter dose found with the same formulation and the Autohaler ${ }^{\mathrm{TM}}$ device.

\section{DISCUSSION}

Scintigraphic imaging has been widely used to assess pulmonary deposition of inhaled drugs. Lung deposition of extrafine aerosol delivered to children via a pMDI and spacer, using different inhalation techniques, has not been previously reported. The present study supported the hypothesis that inhalation of extrafine particles via a pMDI and spacer would result in a high lung dose and show a marked decrease in oropharyngeal and gastrointestinal deposition compared with delivery of the same formulation via an Autohaler ${ }^{\mathrm{TM}}$ [17]. Twodimensional planar scintigraphic images were recorded in order to minimise radiation exposure to children. The present study was limited by the small number of subjects within each age group. However, across all ages $(n=12)$, the study had an acceptable power of $80 \%$.

Tidal breathing, combined with a pMDI and spacer, is a simple inhalation technique for children, as there are no coordination problems associated with inhalation and actuation.

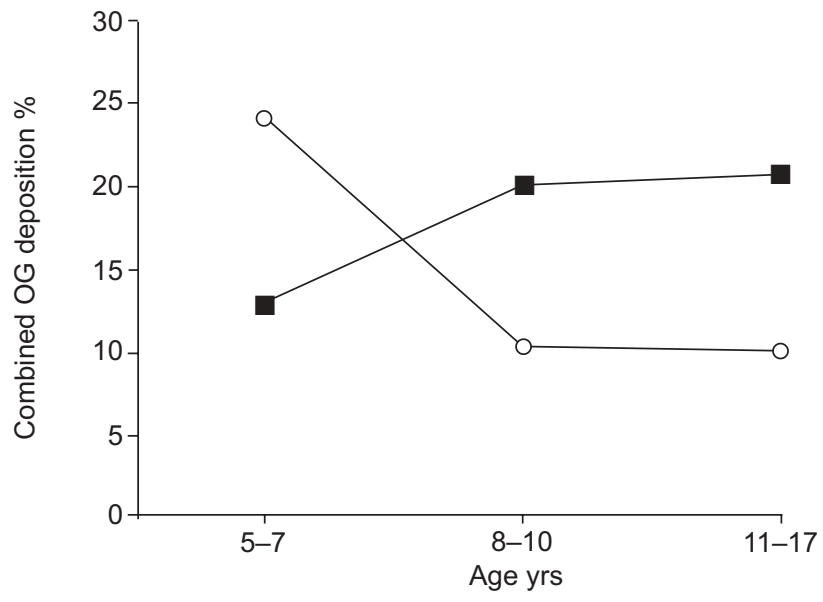

FIGURE 4. Mean oropharynx and gastrointestinal (OG) deposition (\% exactuator dose) for breath-hold $(\mathbf{\square})$ and tidal $(\bigcirc)$ groups. 
The present study has shown that most of the children could obtain lung deposition of $>30 \%$ ex-actuator dose using tidal breathing with a pMDI and spacer. The amount of drug deposited in the lungs of children using tidal breathing tended to increase with both age and lung function, and was remarkably consistent to that shown in children using the same extrafine formulation inhaled via the Autohaler ${ }^{\mathrm{TM}}$ device (37-54\%) [17]. However, the tidal breathing group showed a greater degree of inter-subject variation with a CV $32 \%$. The combined oropharyngeal and gastrointestinal dose deposited in children using a pMDI and spacer was markedly reduced (10-25\%) with the tidal breathing technique compared with the Autohaler $^{\mathrm{TM}}(40-60 \%)$.

With the breath-hold technique, which requires a short training component for children, the present authors have shown high lung dose delivery $(>55 \%$ ex-actuator dose on average) of the extrafine formulation $\mathrm{QVAR}^{\mathrm{TM}}$, independent of age, FEV1, FVC, height and weight and consistent with that shown in adults using the same formulation via a pMDI [14, 27]. There was less variability in the dose to the lungs across all ages, shown by a low inter-subject CV of $11 \%$. Regarding lung deposition in children 5-7 yrs of age, it has also been shown that the single maximal inhalation technique can improve lung deposition almost two-fold (range 51.5-64.8\% ex-actuator) when $\mathrm{QVAR}^{\mathrm{TM}}$ is delivered via a pMDI spacer (Aerochamber Plus $^{\mathrm{TM}}$ ) compared with the Autohaler ${ }^{\mathrm{TM}}$ (range 27.7-46.1\%).

The children aged 5-7 yrs tended to have more oropharyngeal and gastrointestinal drug deposition associated with tidal breathing. This observation may be due to reduced laminar flow of the drug particles and more deposition by inertial impaction in the oropharyngeal region. The improved laminar flow and enhanced gravitational sedimentation associated with a slow single maximal inhalation and breath-hold would be an advantage for younger children with smaller airways. The youngest age group also showed a higher mean P:C ratio for the breath-hold technique (2.5) compared with tidal breathing (2.0). This would indicate that there is more peripheral deposition of the extrafine formulation with the breath-hold technique for this age group. The mean P:C ratio (range) in a previous deposition study with children aged 616 yrs inhaling radiolabelled budesonide from Turbuhaler (AstraZeneca, Lund, Sweden) was 1.7 (1.0-2.4) [28]. Children aged 5-7 yrs have a lower tidal volume and a lower inspiratory flow rate than children aged 8-17 yrs, although these parameters were not recorded. Inhalations $<60 \mathrm{~L} \cdot \mathrm{min}^{-1}$ have been shown to improve peripheral penetration in adults [8].

Children aged 8-17 yrs received similar levels of lung deposition of the extrafine $\mathrm{QVAR}^{\mathrm{TM}}$ formulation, whether using tidal breathing or a single maximal inhalation with a 510-s breath-hold. These children also exhibited similar peripheral penetration of the extrafine drug into the airways with either breathing technique. However, there was less variability in dosing associated with the single maximal inhalation technique. The Aerochamber Plus ${ }^{\mathrm{TM}}$ has a small chamber volume of $149 \mathrm{~mL}$ and was chosen because of its optimal in vitro characteristics, portability and ease of use. However, the small volume may have been the limiting factor which led to an increase in oropharyngeal and gastrointestinal dose in the children aged 8-17 yrs using the breath-hold technique.
Different modes of inhalation are known to affect drug delivery from both dry powder inhalers and pMDIs [8, 2931]. The present study has shown that the single maximal inhalation technique, in combination with Aerochamber Plus $^{\mathrm{TM}}$, can improve the delivery of HFA-BDP to the peripheral airways of children. The increase in oropharyngeal and gastrointestinal deposition associated with breath-hold in patients aged 8-17 yrs may not be clinically relevant, whereas the decreased variability of drug delivery via pMDI spacers with breath-hold in all age groups is an important clinical consideration for drug delivery in children.

Drug distribution patterns obtained from scintigraphic studies provide information on the effectiveness of aerosol delivery to the lungs and therefore provide an important guide to dosage regimens [32]. The present study has demonstrated that the extrafine formulation shows an even, diffuse deposition throughout the airways. It has been suggested that high lung deposition, associated with increased absorption via alveolar deposition, may be linked with higher systemic effects and therefore an increased risk/benefit ratio [12]. Efficacy of $\mathrm{QVAR}^{\mathrm{TM}}$ at half the dose of CFC-BDP [15] means that with regular clinical review and titration of the dose, the improved therapeutic effect associated with targeting the airways could be maintained, while minimising the systemic dose from both lung and oropharyngeal and gastrointestinal deposition. Improved efficacy at a lower dose may result in equivalent control and fewer side-effects [4, 12, 33, 34].

$\gamma$-Scintigraphy has demonstrated that the extrafine formulation results in an even diffuse distribution of $\mathrm{QVAR}^{\mathrm{TM}}$ throughout the lungs of adults and children [14, 16] and the increased peripheral deposition may be associated with improved asthma control [3]. Corticosteroid receptors are located throughout the airways [35] and inflammation extends to the alveoli [1-3]. Computed tomography (CT) has been used to detect structural changes in the airways of infants and children [36]. Functional high-resolution CT imaging has shown that there is reduced airtrapping and improved efficacy when extrafine formulations reach the distal lung [36, 37]. This would indicate the need for more efficient delivery of ICS to the small airways in children with persistent asthma. New inhaled corticosteroid formulations with an extrafine particle size, such as Ciclesonide, should offer both even, diffuse lung deposition, as can be obtained with $\mathrm{QVAR}^{\mathrm{TM}}$, as well as an improved safety profile [38].

In conclusion, the present authors have shown that the spacer inhalation technique can significantly improve lung deposition of the extrafine aerosol delivered via a pressurised metereddose inhaler spacer in asthmatic children aged 5-17 yrs. Tidal breathing with a pressurised metered-dose inhaler and spacer provided adequate lung deposition of the extrafine formulation. However, the slow single maximal inhalation followed by a 5-10-s breath-hold produced less variability in lung dose in all age groups and improved lung deposition in children aged 5-7 yrs almost two-fold. The degree of variability in dosing is an important consideration when optimising formulation, delivery device and inhalation technique for the specific needs of children. Children $\geqslant 5$ yrs of age should be encouraged to use this spacer inhalation technique as soon as practicable. Future recommendations for optimising inhaled drug delivery 
to infants and young children who are unable to perform a slow single maximal inhalation technique could include the combination of pressurised metered-dose inhaler and spacer with an extrafine formulation. Children $\geqslant 2$ yrs of age could be encouraged to perform a more consistent, regular tidal breathing pattern, perhaps with the aid of an incentive spacer device.

\section{ACKNOWLEDGEMENTS}

The authors would like to thank the nuclear medicine technologists J. Wilson and K. Hindley for their technical expertise and assistance.

\section{REFERENCES}

1 Tulic MK, Christodoulopoulos P, Hamid Q. Small airway inflammation in asthma. Respir Res 2001; 2: 333-339.

2 Dubus JC, de Blic J, Mezzi K. The role of the small airways in childhood asthma. Rev Mal Respir 2004; 21: 737-742.

3 Kraft M, Djukanovic R, Wilson S, Holgate ST, Martin RJ. Alveolar tissue inflammation in asthma. Am J Respir Crit Care Med 1996; 154: 1505-1510.

4 Van Asperen PP, Mellis CM, Sly PD. The role of corticosteroids in the management of childhood asthma. The Thoracic Society of Australia and New Zealand. Med J Aust 1992; 156: 48-52.

5 Calpin C, Macarthur C, Stephens D, Feldman W, Parkin PC. Effectiveness of prophylactic inhaled steroids in childhood asthma: a systemic review of the literature. $J$ Allergy Clin Immunol 1997; 100: 452-457.

6 Lawrence M, Wolfe J, Webb DR, et al. Efficacy of inhaled fluticasone propionate in asthma results from topical and not from systemic activity. Am J Respir Crit Care Med 1997; 156: 744-751.

7 Colice GL. Pharmacodynamic and pharmacokinetic considerations in choosing an inhaled corticosteroid. Treat Respir Med 2006; 5: 245-253.

8 Labiris NR, Dolovich MB. Pulmonary drug delivery. Part II: the role of inhalant delivery devices and drug formulations in therapeutic effectiveness of aerosolized medications. Br J Clin Pharmacol 2003; 56: 600-612.

9 Devadason SG, Le Souëf PN. Age-associated factors influencing the efficacy of various forms of aerosol therapy. J Aerosol Med 2002; 15: 343-345.

10 Leach C. Targeting inhaled steroids. Int J Clin Pract Suppl 1998; 96: 23-27.

11 Skoner DP. Balancing safety and efficacy in pediatric asthma management. Pediatrics 2002; 109: Suppl. 2, 381392.

12 Juniper EF, Price DB, Stampone PA, Creeners JP, Mol SJ, Fireman P. Clinically important improvements in asthmaspecific quality of life, but no difference in conventional clinical indexes in patients changed from conventional beclomethasone dipropionate to approximately half the dose of extrafine beclomethasone dipropionate. Chest 2002; 121: 1824-1832.

13 Ederle K. Improved control of asthma symptoms with a reduced dose of HFA-BDP extrafine aerosol: an openlabel, randomised study. Eur Rev Med Pharmacol Sci 2003; 7: $45-55$.
14 Leach CL, Davidson PJ, Boudreau RJ. Improved airway targeting with the CFC-free HFA-beclomethasone metered-dose inhaler compared with CFC-beclomethasone. Eur Respir J 1998; 12: 1346-1353.

15 Davies RJ, Stampone P, O'Connor BJ. Hydrofluoroalkane134a beclomethasone dipropionate extrafine aerosol provides equivalent asthma control to chlorofluorocarbon beclomethasone dipropionate at approximately half the total daily dose. Respir Med 1998; 92: Suppl. A, 23-31.

16 Agertoft L, Laulund LW, Harrison LI, Pedersen S. Influence of particle size on lung deposition and pharmacokinetics of beclomethasone dipropionate in children. Pediatr Pulmonol 2003; 35: 192-199.

17 Devadason SG, Huang T, Walker S, Troedson R, Le Souef PN. Distribution of technetium-99m-labelled QVAR delivered using an Autohaler device in children. Eur Respir J 2003; 21: 1007-1011.

18 Szefler SJ, Warner J, Staab D, et al. Switching from conventional to extrafine aerosol beclomethasone dipropionate therapy in children: a 6-month, open-label, randomized trial. J Allergy Clin Immunol 2002; 110: 45-50.

19 Wildhaber JH, Janssens HM, Pierart F, Dore ND, Devadason SG, Le Souëf PN. High-percentage lung delivery in children from detergent-treated spacers. Pediatr Pulmonol 2000; 29: 389-393.

20 Barry PW, O'Callaghan C. A comparative analysis of the particle size output of beclomethasone diproprionate, salmeterol xinafoate and fluticasone propionate metered dose inhalers used with the Babyhaler, Volumatic and Aerochamber spacer devices. Br J Clin Pharmacol 1999; 47: 357-360.

21 Global initiative for asthma. Global strategy for asthma management and prevention. NHLBI/WHO workshop report: Guidelines and Resources. National Institutes of Health Publication No. 95-3659. Bethesda, National Heart, Lung and Blood Institute, 1995.

22 Knudson RJ, Slatin RC, Lebowitz MD, Burrows B. The maximal expiratory flow-volume curve. Normal standards, variability, and effects of age. Am Rev Respir Dis 1976; 113: 587-600.

23 Macey DJ, Marshall R. Absolute quantitation of radiotracer uptake in the lungs using a gamma camera. J Nucl Med 1982; 23: 731-734.

24 Australian Radiation Protection and Nuclear Safety Agency (ARPANSA). Code of Practice for the Exposure of Humans to Ionizing Radiation for Research Purposes (2005). Radiation Protection Series Publication No. 8. Melbourne, ARPANSA, 2005.

25 Kamiya A, Sakagami M, Hindle M, Byron PR. Aerodynamic sizing of metered dose inhalers: An evaluation of the andersen and next generation pharmaceutical impactors and their USP method. J Pharm Sci 2004; 93: 1828-1837.

26 Dubus JC, Mely L, Huiart L, Marquet C, Le Roux P. Cough after inhalation of corticosteroids delivered from spacer devices in children with asthma. Fundam Clin Pharmacol 2003; 17: 627-631.

27 Leach C. Effect of formulation parameters on hydrofluoroalkane-beclomethasone dipropionate drug deposition in humans. J Allergy Clin Immunol 1999; 104: S250-S252. 
28 Wildhaber JH, Devadason SG, Wilson JM, et al. Lung deposition of budesonide from turbuhaler in asthmatic children. Eur J Pediatr 1998; 157: 1017-1022.

29 Kamps AW, van Ewijk B, Roorda R J, Brand PL. Poor inhalation technique, even after inhalation instructions, in children with asthma. Pediatr Pulmonol 2000; 29: 39-42.

30 Dolovich MB, Ahrens RC, Hess DR, et al. Device selection and outcomes of aerosol therapy: Evidence-based guidelines: American College of Chest Physicians/American College of Asthma, Allergy, and Immunology. Chest 2005; 127: 335-371.

31 Leach CL, Davidson PJ, Hasselquist BE, Boudreau RJ. Influence of particle size and patient dosing technique on lung deposition of HFA-beclomethasone from a metered dose inhaler. J Aerosol Med 2005; 18: 379-385.

32 Wildhaber JH, Monkhoff M, Sennhauser FH. Dosage regimens for inhaled therapy in children should be reconsidered. J Paediatr Child Health 2002; 38: 115-116.

33 Lipworth BJ, Jackson CM. Safety of inhaled and intranasal corticosteroids: lessons for the new millennium. Drug Saf 2000; 23: 11-33.
34 Vanden Burgt JA, Busse WW, Martin RJ, Szefler SJ, Donnell D. Efficacy and safety overview of a new inhaled corticosteroid, QVAR (hydrofluoroalkane-beclomethasone extrafine inhalation aerosol), in asthma. J Allergy Clin Immunol 2000; 106: 1209-1226.

35 Adcock IM, Gilbey T, Gelder CM, Chung KF, Barnes PJ. Glucocorticoid receptor localization in normal and asthmatic lung. Am J Respir Crit Care Med 1996; 154: 771-782.

36 de Jong PA, Muller NL, Pare PD, Coxson HO. Computed tomographic imaging of the airways: relationship to structure and function. Eur Respir J 2005; 26: 140-152.

37 Goldin JG, Tashkin DP, Kleerup EC, et al. Comparative effects of hydrofluoroalkane and chlorofluorocarbon beclomethasone dipropionate inhalation on small airways: assessment with functional helical thin-section computed tomography. J Allergy Clin Immunol 1999; 104: S258-S267.

38 Lee DK, Fardon TC, Bates CE, Haggart K, McFarlane LC, Lipworth BJ. Airway and systemic effects of hydrofluoroalkane formulations of high-dose ciclesonide and fluticasone in moderate persistent asthma. Chest 2005; 127: 851-860. 